Rosa Diana Hernández-Palacios ${ }^{1}$

Velia Ramírez-Amador ${ }^{2}$

Edgar Carlos Jarillo-Soto ${ }^{2}$

María Esther Irigoyen-Camacho ${ }^{2}$

Víctor Manuel Mendoza-Núñez ${ }^{1}$

${ }^{1}$ Unidad de Investigación en Gerontología, Facultad de Estudios Superiores Zaragoza, Universidad Nacional Autónoma de México. Av Guelatao 66, Iztapalapa, Ejército de Oriente. 09230 Ciudad de México México. mendovic@unam.mx ${ }^{2}$ Universidad Autónoma Metropolitana-Xochimilco.

\title{
Relationship between gender, income and education and self-perceived oral health among elderly Mexicans. An exploratory study
}

\author{
Relação entre gênero, renda e educação com a autopercepão \\ da saúde bucal em idosos mexicanos. Um estudo exploratório
}

Abstract The aim of this study was to identify the relationship between sociodemographic factors and self-perceived oral health (SPOH) among the elderly. A cross-sectional, exploratory examination of 150 elderly subjects whose ages ranged from 60-86 was conducted. These subjects used the Geriatric Oral Health Assessment Index (GOHAI) to assess their SPOH. In addition, sociodemographic data were collected from study participants. Data were analyzed using Student's $t$-test, the examination of odds ratio (OR) of logistic regression analysis, the chi-square test, and analysis of variance (ANOVA). The mean decayed, missing, and filled teeth (DMFT) index for the study participants was $20.1 \pm 5.8 ; 21.3 \%$ of subjects were edentulous, and $69.3 \%$ of subjects wore removable dentures. $62.7 \%$ of study participants had poor SPOH (defined as GOHAI score $<44)$. Poor SPOH was significantly more frequent among males $(\mathrm{OR}=2.72,95 \% \mathrm{CI}: 1.03-7.13, p$ $<0.05)$, low-income individuals $(O R=2.7,95 \%$ CI: $1.3-5.8, p<0.01)$, and subjects with less education $(\mathrm{OR}=2.26,95 \%$ CI: 1.1-4.6, $p<0.05)$ than among the overall subject population. The findings suggest that gender (male), low income and low educational levels have a significant influence on the self-perceived oral health status of elderly individuals, irrespective of tooth loss.

Key words Oral health, Gender, Income, GOHAI
Resumo O objetivo deste estudo foi identificar a relação entre os fatores sociodemográficos com a autopercepção da saúde bucal (SPOH) em idosos. Realizou-se um estudo transversal exploratório de 150 idosos. Para avaliar a sua percepção da saúde bucal utilizou-se o Geriatric Oral Assesment Index (GOHAI) e também foram coletados dados sociodemográficos. Os dados foram analisados utilizando o teste T Student, a razão de chances $(\mathrm{OR})$ de análise de regressão logística, o teste Chi Quadrado $(p<0.05)$ e análise de variância ANO$V A$. A média do indice de dentes cariados, perdidos ou obturados (CPO-D) dos participantes no estudo foi de $20.1 \pm 5.8$; $21.3 \%$ foram edêntulos e $69.3 \%$ eram portadores de prótese removivel. O $62.7 \%$ dos participantes no estudo teve pobre autopercepção da saúde bucal (definida com uma suma de GOHAI < 44), a qual foi significativamente mais frequente nos homens $(O R=2.72$, 95\% Cl: 1.03-7.13, $p<0.05)$, com baixa renda $(\mathrm{OR}=2.7,95 \% \mathrm{Cl}: 1.3-5.8, p<0.01)$, e com menor escolaridade $(\mathrm{OR}=2.26,95 \% \mathrm{Cl}$ : 1.1-4.6, $p<0.05)$ do que entre a população em geral. Os resultados presentes sugerem que nos idosos a baixa renda e a menor escolaridade têm influência significativa na autopercepção da saúde bucal, independentemente da perda dentária.

Palavras-chave Saúde bucal, Gênero, Renda, GOHAI 


\section{Introduction}

Oral health and its self-perception are linked to the life quality of older people, which is influenced by socio demographic factors, such as gender, income and education ${ }^{1,2}$. In this sense, most individuals belonging to this social group not only live in poverty and experience marginalization and social inequality but also frequently lack access to health services; moreover, chronic and degenerative diseases abound among this vulnerable group of individuals ${ }^{3}$. These afflictions include mouth diseases, which are regarded as a public health problem because of their high prevalence and incidence, with caries and periodontal disease as the leading causes of tooth loss ${ }^{4,5}$.

Oral health status has traditionally been assessed by objective clinical criteria; however, it has become necessary to consider particular subjective aspects of oral health to attain a more comprehensive understanding of relevant health and disease processes. A questionnaire known as the GOHAI (Geriatric Oral Health Assessment Index), which was developed by Atchison and Dolan, has been used to measure the selfperceived oral health $(\mathrm{SPOH})$ statuses of elderly individuals ${ }^{6-8}$.

This instrument has been validated in several languages and countries for the assessment of the functional, psychological, and social impact of oral conditions on daily life in various sociocultural contexts and the determination of the oral health needs of elderly populations ${ }^{9-13}$. Several studies have addressed the factors that affect SPOH. In such regard, it was found that education and gender were factors associated with poor $\mathrm{SPOH}^{14}$. Similarly, it has been revealed that higher income was associated with better $\mathrm{SPOH}^{15,16}$. Thus, the aim of this study was to identify socio demographic factors associated with self-perceived oral health $(\mathrm{SPOH})$ among elderly subjects.

\section{Methods}

Previous informed consent, an exploratory crosssectional study was carried out in a convenience sample of 150 adults (of both genders) that met the following criteria: (a) interest in participating in the study; (b) literate; (c) absence of handicapping illnesses or serious visual or auditory disabilities. These subjects were selected from 300 elderly adults who regularly attended a public recreation center in the eastern portions of Mexico City. The investigation protocol was approved by the Ethics Committee of the Universidad Nacional Autónoma de México (UNAM) Zaragoza Campus.

\section{Self-perceived oral health (SPOH)}

$\mathrm{SPOH}$ was assessed by administering the Spanish version of the GOHAI questionnaire, which was validated in Mexican older people. This questionnaire assesses the following three dimensions: the psychosocial dimension, which relates to satisfaction with the appearance of teeth, oral health concerns, and social networking limitations caused by oral problems; the physical dimension, which relates to the functions of eating, speaking, and swallowing; and the pain or discomfort dimension, which includes the use of medications to treat oral health problems ${ }^{16}$.

The GOHAI questionnaire includes 12 oral health-related questions. Each item of the questionnaire is scored using the following Likert scale: 0 , never; 1 , rarely; 2 , sometimes; 3 , often; 4, very often; and 5, always. The scores for questions 3,5 , and 7 are encoded in reverse order. We did an analysis of percentiles, and it was established as cutoff point the value of the first quartile ( $\leq 44$ score) for poor SPOH statuses and third quartile (GOHAI $\geq 51$ score) for good SPOH.

\section{Sociodemographic variables}

A questionnaire was administered to the study subjects to assess the following sociodemographic variables: age, sex, marital status, education, income, and the identities of other persons living with the subject. Subjects were classified into the following three age categories: 60-69 years, 70-79 years, and $>80$ years. With respect to education, subjects were classified into the following three categories based on the number of years of schooling they had received: 0-6 years, 7-9 years, and $>9$ years. On the other hand, we did an analysis of percentiles related to income, and it was established as cutoff point the value of the first quartile ( $\leq$ US\$154) for lower income.

\section{Oral health status}

After this questionnaire had been administered to the subjects, an oral examination was performed in which a light source and plane mirror were used to evaluate the oral health 
status of the elderly study participants. This examination was conducted by a female dentist who was previously standardized to perform the measurements, obtaining a Kappa value of 0.85 . In accordance with World Health Organization (WHO) criteria, dental caries were assessed using the decayed, missing, and filled teeth (DMFT) index, which accounts for teeth that are decayed, missing, filled by restorative dental work, and healthy ${ }^{17}$. The denture-wearing practices of the elderly study participants were also recorded.

\section{Statistical Analysis}

Data were analyzed with the SPSS 16.0 statistical software package, which was used to obtain descriptive statistics for the study variables. Student's t-test and analysis of variance (ANOVA) were used to determine the statistical significance of quantitative variables, and the chi-square test with a 95\% confidence level was used to assess qualitative variables. Odds ratios (ORs) of logistic regression analysis with their associated 95\% confidence intervals (CIs) were used to calculate risk estimates, were considering as independent variables (age, gender, income, live alone, schooling, DMFT, uses dentures, and tooth loss) and possible risk factors for poor SPOH statuses $(\geq 44)$. An OR $>1$ and the associated CI did not include $1(\mathrm{p}<0.05)$ was considered as risk factor.

\section{Results}

The study involved a total of 150 participants, including 119 (79.3\%) women and 31 (20.7\%) men. The mean age of the study subjects was $67 \pm 6.4$ years. In addition, $76(50.6 \%)$ study participants were married, 53 (35.3\%) study participants were widowed, and $62(41.3 \%)$ study participants lived with their children.

With respect to education, 86 (57.4\%) study subjects reported that they had six or fewer years of schooling; with respect to income, $63(42 \%)$ study subjects reported having a monthly income of no more than US\$154. The mean value of the overall DMFT index for the study subjects, which described the general oral health status of the examined population, was $20.1 \pm 5.8$. The following mean values were observed for specific components of the DMFT index: $5.6 \pm 5.4$ for sound teeth, $1.5 \pm 2.0$ for decayed teeth, $6.5 \pm 5.6$ for filled teeth, and $12.0 \pm 8.6$ for missing teeth. Notably, $51 \%$ of study participants (77 subjects) had ten or more missing teeth, and $21.3 \%$ (32 subjects) of study participants were edentulous (i.e., these subjects had lost all of their teeth).

The mean GOHAI score for the study subjects was $46.5 \pm 8.1$, with a minimum score of 25 and a maximum score of 60. GOHAI scores were significantly lower among the group of low-income elderly individuals than among the medium- to high-income group of study subjects $(41.5 \pm 9.9$ versus $45.8 \pm 10.5, \mathrm{p}<0.01)$. GOHAI scores did not significantly differ for subjects of different genders $(44.5 \pm 11.3$ (for male) versus $43.8 \pm 10.2$ (for female), $\mathrm{p}>0.05$ ) (Table 1).

With respect to $\mathrm{SPOH}$, poor, normal, and good SPOH statuses were reported by 94 (62.6\%), $42(28.0 \%)$, and $14(9.3 \%)$ of the elderly subjects of this study, respectively. The classification of study participants by gender revealed that $69.8 \%$ of female study subjects and $35.5 \%$ of male study subjects had poor SPOH (Table 2).

Table 3 indicates the distribution of responses received from the elderly study subjects for each question of the GOHAI questionnaire. Notably, $66 \%$ (99) of the study participants reported problems with chewing, $90.6 \%$ (136) of the study participants reported discomfort when eating, 84\% (126) of the study participants were unhappy with the appearance of their teeth, and $64 \%$ (96) of the study participants were required to alter the types of food they consumed because of problems with their teeth or dentures.

With respect to the risk factors associated with poor SPOH (GOHAI score $\leq 44$ ), poor $\mathrm{SPOH}$ statuses were significantly more frequent among male subjects (OR $=2.72$, 95\% CI: 1.03 $7.13, \mathrm{p}<0.042)$, low-income subjects $(\mathrm{OR}=2.7$, 95\% CI: $1.3-5.8, \mathrm{p}<0.007)$, and subjects with lower education levels $(\mathrm{OR}=2.26,95 \% \mathrm{CI}$ : 1.1 $4.6, \mathrm{p}<0.02)$ than among the entire population of study subjects. Also, high tooth loss $\geq 12$ teeth) was risk factor for poor SPOH (OR $=16.9,95 \%$ CI: 6.6-42.7, $\mathrm{p}<0.04$ ) (Table 4).

\section{Discussion}

Major oral health problems experienced by elderly individuals include dental caries, periodontal disease, and disorders related to the prolonged and improper use of dentures ${ }^{18-20}$. Moreover, assessments of SPOH among elderly subjects have revealed that $>80 \%$ of elderly individuals have concerns regarding their oral health and/or poor SPOH status ${ }^{11,21,22}$. This phenomenon cannot be attributed merely to 


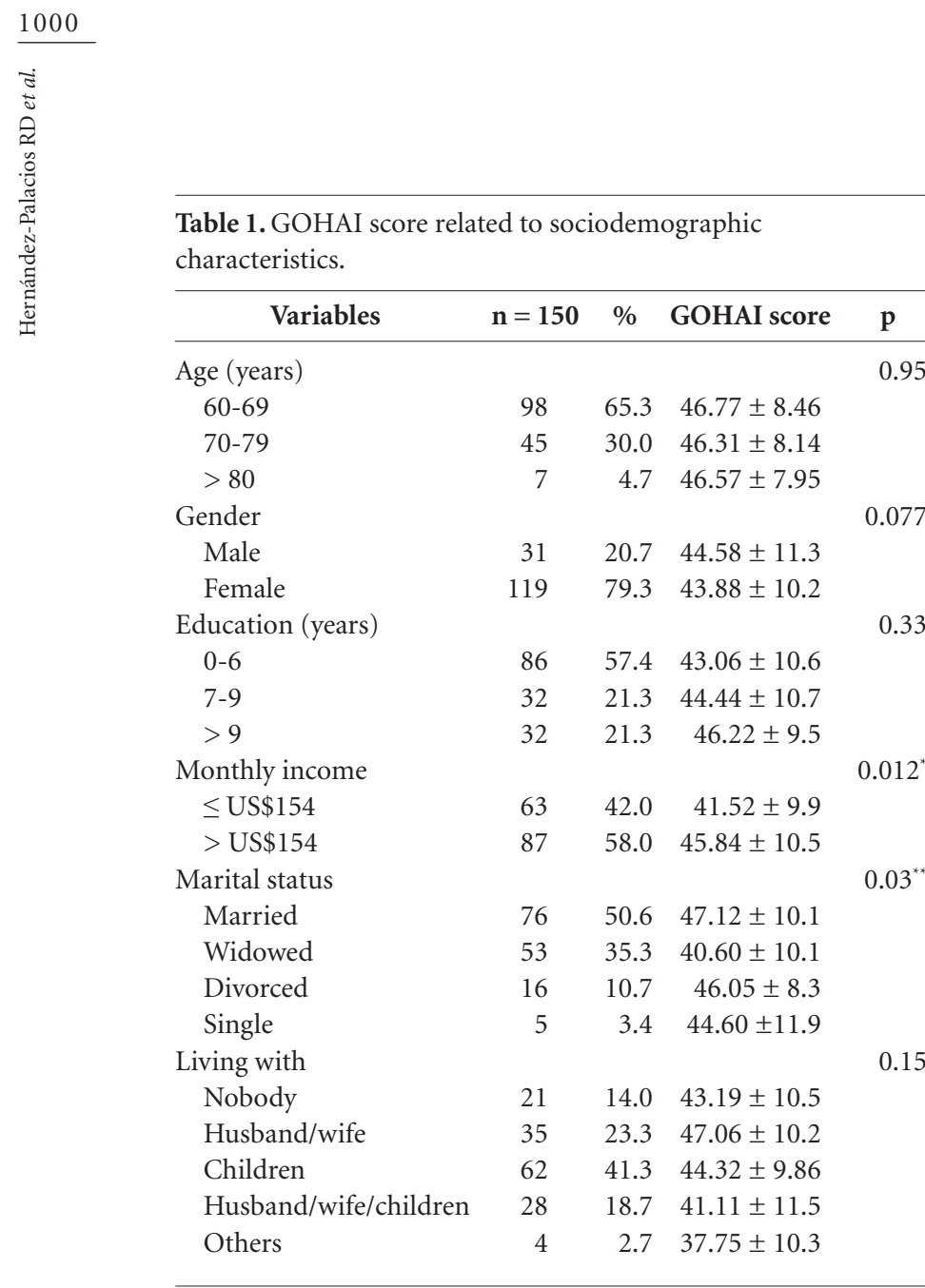

GOHAI, General Oral Health Assessment Index. Data are presented as means \pm SD. ${ }^{*}$ Student's t-test, ${ }^{* *}$ ANOVA.

Table 2. SPOH status frequencies among elderly Mexicans by sex.

\begin{tabular}{lrrrr}
\hline \multicolumn{1}{c}{ Gender } & $\begin{array}{c}\text { Good } \\
\mathbf{2} \mathbf{5 1}\end{array}$ & $\begin{array}{c}\text { Normal } \\
\mathbf{4 5 - 5 0}\end{array}$ & $\begin{array}{r}\text { Poor } \\
\mathbf{5} \mathbf{4 4}\end{array}$ & \multicolumn{1}{c}{ Total } \\
\hline Female (\%) & $9(7)$ & $27(23)$ & $83(70)$ & $119(100)$ \\
Male (\%) & $5(16)$ & $15(48)$ & $11(36)$ & $31(100)$ \\
Total (\%) & $14(9)$ & $42(28)$ & $94(63)$ & $150(100)$
\end{tabular}

SPOH, self-perceived oral health.

age; in particular, a report from Latin America has indicated that more than $70 \%$ of examined institutionalized elderly individuals exhibited good $\mathrm{SPOH}$ statuses ${ }^{22}$. In combination, the aforementioned findings suggest that living conditions, sociocultural characteristics, and the availability of health services are important determinants of $\mathrm{SPOH}$.

In the current study, a relationship was observed between sociodemographic conditions and SPOH among the examined elderly subjects; for instance, risk factors for poor SPOH included a low income and a low educational level. These findings are similar to the results reported by Brennan \& Spencer ${ }^{23}$, who found that poor $\mathrm{SPOH}$ is related to income and to a low educational level. Similarly, López Soto et al. ${ }^{24}$ found that individuals with poor $\mathrm{SPOH}$ also tended to have low educational levels. Likewise, Tsakos et al. ${ }^{25}$ in a study with community-dwelling non-disabled people $65 \mathrm{yr}$ of age and older, from suburban London found that the low educational level has an independent negative impact on poor $\mathrm{SPOH}$; and de Andrade et al. ${ }^{26}$ observed that sufficient income and higher schooling ( $\geq$ years 8 ) are associated with significantly better GOHAI scores in elderly Brazilians; also Fuentes-García et al. ${ }^{27}$ found similar results in community-dwelling older people of three cities in South America (Santiago, Chile; Buenos Aires, Argentina and Montevideo, Uruguay).

These findings suggest that individuals with low incomes and low educational levels must first satisfy their basic needs, such as food, clothing, and transportation, before addressing oral health; thus, oral health may be a relatively low priority among low-income, relatively uneducated elderly individuals. On the other hand, it is necessary to assess lifestyles associated with cultural characteristics linked to oral health care; for instance, several participants in the current study stated that when they were children, their families not only lacked the toothbrushes and toothpaste required for practicing good oral hygiene but also ignored the importance of keeping their teeth in good condition. These study participants could not access health services and did not receive timely dental care for the detection of oral problems. Thus, these individuals only sought medical care after oral pathological processes had reached an advanced stage; given that conservative treatments are generally expensive, they typically chose the option of dental extraction, leading to the gradual loss of teeth observed to be associated with poor $\mathrm{SPOH}$.

In this study, we observed a higher frequency of poor SPOH (GOHAI score $\leq 44$ ) in the male group. This finding contrasts with the results reported by Locker \& Slade ${ }^{8}$ who observed that oral health and pain issues are a greater concern for female gender than for male; this suggests that gender-related sociocultural characteristics may be determinants of individuals' lifestyles with respect to oral health, function, and aesthetics. 
Table 4. Factors associated with poor self-perceived oral health $(\mathrm{GOHAI} \leq 44)$.

\begin{tabular}{lrrr}
\hline \multicolumn{1}{c}{ Factor } & OR & 95\% CI & p-value \\
\hline Age ( $\geq$ 69 years) & 0.6 & $0.3-1.2$ & 0.15 \\
Sex (male) & 2.7 & $1.0-7.1$ & 0.042 \\
Income ( $\leq$ US $\$ 154$ /month) & 2.7 & $1.3-5.8$ & 0.007 \\
Live alone & 0.5 & $0.3-0.7$ & 0.001 \\
Schooling ( $\leq 6$ years) & 2.2 & $1.1-4.6$ & 0.024 \\
DMFT ( $\geq 14)$ & 0.8 & $0.3-2.1$ & 0.81 \\
Uses dentures & 3.0 & $0.8-10.3$ & 0.07 \\
Tooth loss ( $\geq 12$ teeth) & 16.9 & $6.6-42.7$ & 0.04
\end{tabular}

OR, Odds ratio. Logistic regression analysis.

In addition, results from the current study indicated that married subjects reported better $\mathrm{SPOH}$ levels than unmarried subjects. This finding is consistent with observations by Kressin et al. $^{28}$, who concluded that married subjects exhibited high GOHAI scores. These results suggest that individuals with partners will devote greater attention to their oral health than individuals without partners because the partnered individuals must please or at least live with another person and will therefore engage in higher levels of personal care in general and health care in particular.

Based on the cutoff thresholds established for Anglo-Saxon populations, the mean GOHAI score obtained in the present study $(46.5 \pm 8.1)$ corresponds to poor $\mathrm{SPOH}^{6}$. However, this mean GOHAI score is similar to not only the mean GOHAI score ( $45.84 \pm 7.0)$ observed in a study of institutionalized elderly Mexican subjects 16 but also the mean GOHAI score (42.6) obtained in a Chilean study ${ }^{15}$. These findings suggest that poor oral health among elderly individuals in Latin America is a consequence of economic conditions and a lack of access to dental health services; these issues lead to the deterioration of their oral health and consequently produce poor SPOH. In this study, measurements using the DMFT index indicated that dental care greatly impacted oral health. For the examined subjects, a mean DMFT value of 20.1 affected teeth was obtained; the major component of this DMFT value was missing teeth, with an average of 12 teeth missing per study participant. In this sense, several studies have reported that the tooth loss in a predictor of poor cognitive function in community-dwelling adults older ${ }^{29-31}$. On the other hand, Zuluaga et al. ${ }^{32}$ found a significantly better GOHAI scores in elderly with mild cognitive impairment (MCI) than cognitively normal residents in nine geriatric institutions in the Spanish province of Granada. Therefore suggest administer cognitive screening combined with applying any $\mathrm{OH}-\mathrm{QoL}$ instrument would make the results more reliable.

Thus, we can assert that elderly experience a high magnitude and severity of dental caries, a phenomenon that is associated with living conditions and with limited access to dental health services. Therefore, it is urgent to implement 
programs to promote oral health in the context of active aging ${ }^{33,34}$, that incorporate preventive practices and timely dental care at the community level and can thereby forestall irreversible dental damage and subsequent tooth loss. In addition, this study found that $21.3 \%$ of the examined elderly subjects were edentulous.

In such regard, it has been observed that the rates of edentulism differ in each ethnic group, which is determined by conditions and life styles ${ }^{35,36}$. Notably, the high incidence of edentulism has been erroneously regarded as a normal aging-related change.

Most dental treatments received by lowincome elderly are crippling in nature because these treatments are less expensive than more conservative approaches. Thus, these treatments affect biological, psychological, and social domains and thereby influence $\mathrm{SPOH}$. In accordance with this reasoning, TrejoJuaréz et al. ${ }^{11}$ observed an inverse relationship between DMFT scores and positive psychosocial perceptions.

Overall, the results of our study demonstrate an inverse association between GOHAI score and tooth loss. In particular, our findings showed that elderly subjects with more than 12 missing teeth are more likely to have poor SPOH statuses. It has been observed a relationship between the oral health status with the difficulties in acquiring and preparing food; these difficulties, in combination with social abandonment issues, a diminished support network, and psychological problems such as depression, can exacerbate the nutritional problems of elderly individuals ${ }^{37}$.

The results of the current study also indicated that because the ability of edentulous elderly individuals to chew correctly is determined by denture function, the use of an ill-fitting denture is associated with poor SPOH among the examined elderly subjects. Moreover, it was determined that dentures worn by elderly adults were frequently damaged and ill-fitting due to long use and a lack of a periodic examination of denture fit by a dentist. Importantly, the study participants who used dental dentures generally exhibited poor $\mathrm{SPOH}$ statuses; this phenomenon could be caused by a lack of appropriate followup to ensure that dentures fit correctly. In this sense, Albaker ${ }^{38}$ found that the mean GOHAI score was significantly lower $(\mathrm{p}<0.05)$ among participants who had conventional denture on both upper and lower jaw (28.25 \pm 3.67$)$, as compared to those who had conventional denture only on one arch.

Among the limitations of the current study, we emphasize that this research is a cross-sectional study with a convenience sample, the percentage of women was significantly higher than men and age 60 to 69 years group was significantly more numerous, hence is not representative; we suggest that a longitudinal study with a large representative sample of individuals both sexes, more age groups, and different contexts should be conducted to confirm our findings.

\section{Conclusion}

The elderly are considered to be a vulnerable group because of their living conditions frequently deteriorate over time. Our study demonstrated that poor SPOH is associated with gender (male), low income and low educational level, independently and poor oral health. SPOH affects not only functional and psychological characteristics but also social relationships. Therefore, the living conditions of elderly adults must be improved, and preventive programs for active aging that can prevent tooth loss and the associated biological, psychological, and social consequences must be developed. 


\section{Collaborations}

RD Hernandez-Palacios participated in the design of this study and the collection, analysis, and interpretation of study data. EC JarilloSoto participated in the development of study concepts and the drafting of the paper. ME Irigoyen-Camacho participated in data analysis. $\mathrm{V}$ Ramirez-Amador participated in the design of the study. M Mendoza-Núñez participated in the analysis and interpretation of study data and the drafting of this paper.

\section{Acknowledgements}

This work was supported by Dirección General de Asuntos del Personal Académico, Universidad NacionalAutónoma deMéxico(DGAPA,UNAM).

\section{References}

1. Skaar DD, Hardie NA. Demographic factors associated with dental utilization among community dwelling elderly in the United States, 1997. J Public Health Dent 2006; 66(1):67-71.

2. Skaar DD, O'Connor H. Dental service trends for older US adults, 1998-2006. Spec Care Dentist 2012; 32(2):42-48.

3. Wong R, Espinoza M, Pallono A. Adultos mayores mexicanos en contexto socioeconómico amplio: salud y envejecimiento. Salud Publica de Mex 2007; 49(Supl. 4):S436- S447.

4. Soto-Sámano C, Rubio-Cisneros J, Taboada-Aranza O, Mendoza-Núñez VM. Patología bucal en el senecto: un estudio exploratorio. Dentista y Paciente 1998; $7(74): 20-26$.

5. Irigoyen ME, Velázquez C, Zepeda M, Mejía A. Caries dental y enfermedad periodontal en un grupo de personas de 60 años o más de edad de la ciudad de México. Rev ADM 1999; 44(2):64-69.

6. Atchison KA, Dolan TA. Development of the Geriatric Oral Health Assessment Index. J Dent Educ 1990; 54(11):680-687.

7. Locker D. Clinical correlates of changes in self-perceived oral health in older adults. Community Dent Oral Epidemiol 1997; 25(3):199-203.

8. Locker D, Slade G. Association between clinical and subjective indicators of oral health status in an older adult population. Gerodontology 1999; 11(2):108-114.

9. Arlette S, Zunzunegui MV. Detección de necesidades de atención bucodental en ancianos mediante la autopercepción de la salud oral. Rev Multidisciplinaria de Gerontología 1999; 9(4):216-224.

10. Tubert-Jeannin S, Riordan P, Morel-Papermot A, Porcheray S, Saby-Collet S. Validation of an oral health quality of life index (GOHAI) in France. Community Dent Oral Epidemiol 2003; 31(4):275-284.

11. Trejo-Juárez EP, Rangel-Aldama R, Martínez-Zambrano IA, Hernández-Palacios RD, Mendoza-Núñez VM. Relación entre el índice de caries dental (CPOD) con la percepción psicosocial en una población de adultos mayores. Rev Archivos de Geriatría 2004; 71(6):17-20.

12. Naito M, Suzukamo Y, Nakayama T, Hamajima N, Fukuhara S. Linguistic adaptation and validation of the General Oral Health Assessment Index (GOHAI) in an elderly Japanese population. J Public Health Dent 2006; 66(4):273-275.

13. Momen A. Arabic version of the geriatric oral health assessment index. Gerodontology 2008; 25(1):34-41.

14. Afonso-Souza G, Nadanovsky P, Chor D, Faerstein E, Werneck GL, Lopes CS. Association between routine visits for dental checkup and self-perceived oral health in an adult population in Rio de Janeiro: the PróSaúde Study. Community Dent Oral Epidemiol 2007; 35(5):393-400.

15. Montes J. Impacto de la salud oral en la calidad de vida del adulto mayor. Rev Dental de Chile 2001; 92(3):2931.

16. Sánchez-García S, Heredia-Ponce E, Juárez-Cedillo T, Gallegos-Carrillo K, Espinel-Bermúdez C, de la Fuente-Hernández J, García-Peña C. Psychometric properties of the General Oral Health Assessment Index (GOHAI) and dental status of an elderly Mexican population. J Public Health Dent 2010; 70(4):300-307. 
17. World Health Organization (WHO). Oral health surveys, indices and methods for measurement of dental disease. $4^{\text {th }}$ ed. Geneva: WHO; 1997.

18. Taboada-Aranza O, Mendoza-Núñez VM, MartínezZambrano I. Prevalencia y severidad de la enfermedad parodontal. Dentista y Paciente. Rev Universidad Tecnológica de México 2000; 8(9):10-16.

19. Valdez-Penagos G, Mendoza-Núñez VM. Relación del estrés oxidativo con la enfermedad periodontal en adultos mayores con diabetes mellitus tipo 2. Rev ADM 2006; 80(5):189-194.

20. Martínez-Zambrano IA, Hernández-Palacios RD García-Barrera MJ, Mendoza-Núñez VM. Prevalencia y factores de riesgo de candidosis eritematosa crónica en una población de adultos mayores usuarios de prótesis dentales totales y removibles. Medicina Oral 2008; 10(1):12-15.

21. Esquivel R, Jiménez J. Necesidades de atención odontológica en adultos mayores mediante la aplicación del GOHAI. Rev ADM 2010; 67(3):127-132.

22. Piuvezam G, de Lima KC. Self-perceived oral health status in institutionalized elderly in Brazil. Arch Gerontol Geriatr 2012; 55(1):5-11.

23. Brennan D, Spencer J. Life events and oral health related quality of life among young adults. Qual Life Res 2009; 18(5):557-565.

24. López-Soto OP, Cardona-Rivas D, Parra-Sánchez H, Montes-Rojas DM, Arango-Ossa MA. Morbilidad oral y factores de riesgo en adultos mayores. Revista Digital Salud 2005; 1 .

25. Tsakos G, Sheiham A, Iliffe S, Kharicha K, Harari D, Swift CG, Gillman G, Stuck AE. The impact of educational level on oral health related quality of life in older people in London. Eur J Oral Sci 2009; 117(3):286-292.

26. Andrade FB, Lebrão ML, Santos JL, Cruz Teixeira DS Oliveira Duarte YA. Relationship between oral health related quality of life, oral health, socioeconomic, and general health factors inelderly Brazilians. J Am Geriatr Soc 2012; 60(9):1755-1760.

27. Fuentes-García A, Lera L, Sánchez H, Albala C. Oral health-related quality of life of older people from three South American cities. Gerodontology 2013; 30(1):6775 .

28. Kressin NR, Atchison KA, Miller DR. Comparing the impact of oral disease in two populations of older adults: application of the geriatric oral health assessment index. J Public Health Dent 2007; 57(4):224-232.
29. Kaye EK, Valencia A, Baba N, Spiro A 3rd, Dietrich T, Garcia RI. Tooth loss and periodontal disease predict poor cognitive function in older men. J Am Geriatr Soc 2010; 58(4):713-718.

30. Park H, Suk SH, Cheong JS, Lee HS, Chang H, Do SY, Kang JS. Tooth loss may predict poor cognitive function in community-dwelling adults without dementia or stroke: the PRESENT project. J Korean Med Sci 2013; 28(10):1518-1521.

31. Lexomboon D, Trulsson M, Wårdh I, Parker MG. Chewing ability and tooth loss: association with cognitive impairment in an elderly population study. J Am Geriatr Soc 2012; 60(10):1951-1956.

32. Zuluaga DJ, Montoya JA, Contreras CI, Herrera RR. Association between oral health, cognitive impairment and oral health-related quality of life. Gerodontology 2012; 29(2):e667-673.

33. Martínez-Maldonado ML, Correa-Muñoz E, Mendoza-Núñez VM. Program of active aging in a rural Mexican community: a qualitative approach. BMC Public Health 2007; 7:276.

34. Mendoza-Núñez VM, Martínez-Maldonado ML, Correa -Muñoz E. Implementation of an active aging model in Mexico for prevention and control of chronic diseases in the elderly. BMC Geriatrics 2009; 9:40.

35. Wu B, Liang J, Plassman BL, Remle C, Luo X. Edentulism trends among middle-aged and older adults in the United States: comparison of five racial/ethnic groups. Community Dent Oral Epidemiol 2012; 40(2):145-153.

36. Wu B, Liang J, Landerman L, Plassman B. Trends of edentulism among middle-aged and older Asian Americans. Am J Public Health 2013; 103(9):e76-82.

37. Sánchez-García S, Juárez-Cedillo T, Reyes-Morales $\mathrm{H}$, Fuente-Hernández J, Solórzano-Santos F, García-Peña C. Estado de la dentición y sus efectos en la capacidad de los ancianos para desempeñar sus actividades habituales. Salud Publica Mex 2007; 49(3):173-181.

38. Albaker AM. The oral health-related quality of life in edentulous patients treated with conventional complete dentures. Gerodontology 2013; 30(1):61-66

Article submitted 14/06/2014

Approved 01/10/2014

Final version submitted 12/10/2014 